\title{
Large-Eddy Simulation of Microvortex Generators in a Turbulent Boundary Layer
}

\author{
Andrew P. Heffron ${ }^{1}$, John J. Williams ${ }^{2}$, and Eldad Avital ${ }^{3}$ \\ Queen Mary, University of London, London, UK
}

The present study investigates the flow physics on MicroVortex Generators (MVGs) in order to improve the performance in turbulent boundary layers (TBLS). TBLs can be a challenging environment to MVGs because of the streamwise length of the shedded vortex and the increased parasitic drag of the MVGs. Large-Eddy Simulation (LES) is used to properly resolve the turbulent boundary layer with a zeropressure gradient and the MVG. Three different vane-types are investigated (e423-Mod, triangular, and rectangular vanes) and studied in a single vane configuration. A separation bubble is found on the leading edge of the rectangular vanes which introduces unsteadiness into the vortex formation. The e423-Mod and triangular vanes are more aerodynamic efficient by preventing a separation bubble from forming. However, the vortex generated from the triangular vane forms is formed to close to the wall causing it to rapidly decay. The e423-Mod vane avoids this problem but its drag is very high relative to the strength of the generated vortex, decreasing its efficiency. Using the ratio of the circulation strength of the vortex to the drag of the vane, the triangular vane is confirmed to be the most efficient if evaluated at $10 \mathrm{~h}$ behind the vane, where $h$ is the MVG's height. However, the rapid decay of the vortex from the triangular vane further downstream in the TBL allows the rectangular vane at $16^{\circ}$ to become the most efficient MVG due to its lower decay rate, demonstrating the need to consider a range of issues when designing an MVG.

$\begin{array}{ll}C_{D} & \text { Drag coefficient based on freestream velocity } \\ e & \text { Length of MVG vane } \\ e^{*} & \text { Transformed length of MVG vane }(e \cos (\alpha)) \\ h & \text { Height of MVG vane } \\ h^{+} & \text {Effective height of MVG vane }\left(\frac{U_{\tau} h}{v}\right)\end{array}$

\footnotetext{
${ }^{1}$ PhD Student, School of Engineering and Material Science, a.p.heffron@qmul.ac.uk, Non-AIAA Member.

${ }^{2}$ Emeritus Professor of Computational Fluid Dynamics, j.j.r.williams@qmul.ac.uk, Non-AIAA Member.

${ }^{3}$ Reader in Computational Fluids and Acoustics, e.avital@qmul.ac.uk, Senior AIAA Member (Corresponding Author).
} 


$\begin{array}{ll}\hat{n} & \text { Unit vector } \\ U_{\tau} & \text { Friction velocity } \\ U_{o} & \text { Freestream velocity } \\ R e & \text { Reynolds number based on the freestream velocity }\left(\frac{U_{o} h}{v}\right) \\ x & \text { Streamwise direction } \\ y & \text { Spanwise direction } \\ z & \text { Vertical direction } \\ \delta & \text { Boundary layer thickness } \\ \Gamma & \text { Circulation } \\ \Gamma^{+} & \text {Non-dimensional circulation }\left(\frac{\Gamma}{u_{\tau} h}\right) \\ \tau & \text { Shear stress } \\ \omega & \text { Vorticity } \\ \langle u\rangle & \text { Mean component } \\ u^{\prime} & \text { Fluctuating component }\end{array}$

\section{Introduction}

Flow separation is a problem found in many fluid dynamic applications that can lead to large energy losses in the fluid flow. Many design strategies have been developed to minimize and prevent flow separation, and a commonly used strategy to inhibit flow separation is to use vortex generations (VGs). Vortex generators generate vortices that transfer momentum from the outer to the inner boundary layer which improves the state of the boundary layer.

Several decades of research on VGs have led to a significant refinement to their design and implementation. Early VGs had heights equal to the boundary layer height but research by Rao and Kariva [1] found vortex generators with a height of $h / \delta \leq 0.65$ could be just as effective at transferring momentum in the boundary. Experimental research by Lin [2] found that VGs that generated streamwise vortices that are generated by vane-type VGs were the most effective in delaying flow separation on their experiments high-lift airfoil. Further work by Lin et al. [2,3] found that vane-type VGs could be reduced to $h / \delta \sim 0.2$ to reduce their drag while retaining their effectiveness in suppressing separation. Further 
reduction in the height of VGs however found to reduce their effectiveness. Lin [2] called these subboundary VGs 'MicroVortex Generators' (MVGs). In regards to the best MVG configuration, work by Pauley and Eaton [4] found the optimum vane angle to be $18^{\circ}$ on a flat plane. Godard and Stanislas [5] similarly found $18^{\circ}$ to be the optimum angle on an airfoil section in addition to triangular vanes being the most efficient MVG shape. Previous research by the authors [6] have confirmed these conclusions.

For an isolated vortex in a turbulent boundary layer, the vortex decays by friction with the wall [4]. Shabaka et al. [7] noted that the skin friction is strongest at the downdraft of the vortex on the wall and weakest at the updraft of the vortex. Studying the vortex transport equation, the vortex diffuses by strong gradients in the normal stress anisotropy $\left(\left\langle v^{\prime} v^{\prime}\right\rangle-\left\langle w^{\prime} w^{\prime}\right\rangle\right)$ and crossflow-plane shear stress $\left\langle v^{\prime} w^{\prime}\right\rangle$ of the flow [4, 8]. However, the decay and diffusion of the vortex is slow, allowing for the vortex to persist up to $100 \mathrm{~h}$ behind the vane [2,9]. Lin et al. [2] suggested that the optimum distance was $5 \mathrm{~h}$ to $10 \mathrm{~h}$ between a MVG and the separation point. The vortex has been observed to wander in the spanwise and normal direction with the motion being controlled by the wall (vortex image) and the turbulent boundary layer [10].

Work by Ashill et al. [11, 12], Allan et al. [13], and Wik et al. [14] established that RANS is very capable of modelling the global characteristics of MVGs in turbulent boundary layers (TBLs) for simple cases. Furthermore, Ashill et al. [12] found RANS modelling gave reasonable prediction of drag of the MVG vanes when compared to experimental values. However, the assumptions and limitations of RANS modelling may prevent the full capture of all the flow physics found on MVG vanes embedded in the boundary layer, particularly on the vane itself. In contrast to RANS modeling, Large Eddy Simulation (LES) resolves the turbulent boundary layer and enables the capturing of important features that RANS modelling may exclude. Previous authors have used LES to simulate MVGs $[8,15,16]$ or detailed experimental measurements $[7,9,10,17]$ but have primarily focused on the downstream behavior of vortex and/or the global performance of the devices. This paper seeks to study the flow behavior directly on the MVG when embedded in a TBL and how it influences the downstream behavior of the vortex. Further focus is given to the drag of the MVG vanes which has received limited attention in literature. The combination of these two areas of focus seeks to improve the understanding of how to efficiently implement and design MVG systems for TBLs. 


\section{Numerical Method and Setup}

To solve the incompressible Navier-Stokes equations, the open sourced CFD code Code_Saturne, ideveloped by Électricté de France (EDF), was used. Code_Saturne is based upon an unstructured, collocated finite volume method. The code has been optimized for a HPC environment [18]. Code_Saturne was compiled and run with ParMetis graph partitioning library on ARCHER HPC, part of EPCC. The pressure-velocity coupling is solved with a non-iterative PISO scheme with a Rhie and Chow interpolation scheme. For large-eddy simulation in Code_Saturne, an implicit 2nd-order Crank-Nicholson time scheme and a 2nd-order centered scheme was used for spatial discretization. Code_Saturne solves the incompressible, filtered Navier-Stokes equations:

$$
\begin{gathered}
\frac{\partial \tilde{u}_{i}}{\partial x_{i}}=0 \\
\frac{\partial \tilde{u}_{i}}{\partial t}+\frac{\partial \tilde{u}_{i} \tilde{u}_{j}}{\partial x_{j}}-v \frac{\partial^{2} \tilde{u}_{i}}{\partial x_{i} \partial x_{j}}=-\frac{1}{\rho} \frac{\partial \tilde{P}}{\partial x_{i}}-\frac{\partial \tau_{i j}}{\partial x_{j}}
\end{gathered}
$$

The stress tensor $\tau_{i j}$ is solved via the Boussinesq hypothesis

$$
\tau_{i j}-\frac{1}{3} \tau_{k k} \delta_{i j}=-2 \mu_{t} \tilde{S}_{i j}
$$

The unresolved turbulent viscosity is modeled with the WALE (Wall-Adapting Local Eddy-Viscosity) subgrid models. To ensure numerical stability and accuracy, a time step was chosen that kept the CFL number below 0.65 .

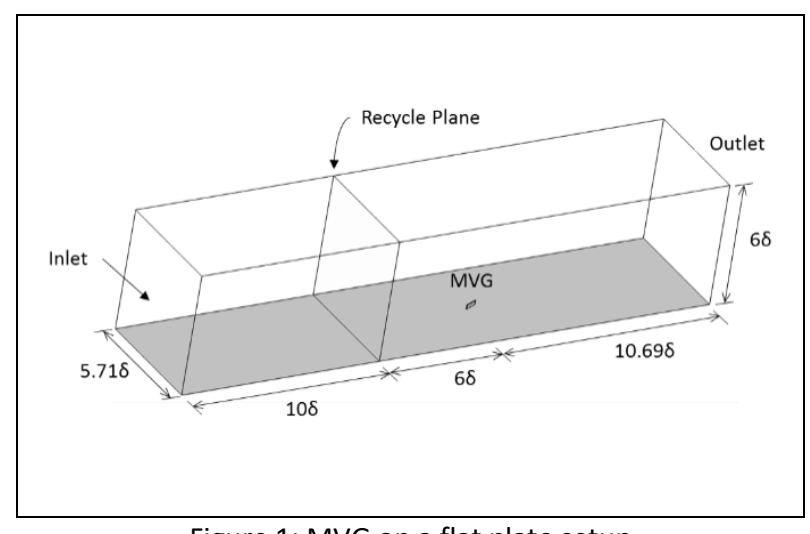

Figure 1: MVG on a flat plate setup

The computational domain for a MVG on a flat plate is shown in Fig. 1. A boundary layer of $35 \mathrm{~mm}$ and a freestream velocity of $6.176 \mathrm{~m} / \mathrm{s}$ was imposed at the inlet to obtain a $\operatorname{Re}_{h}$ of 2900 . The height of the MVG vane was scaled to $20 \%$ of the boundary layer thickness; based on the freestream velocity and height of the MVG, the Reynolds number was 2,894 . The Reynolds number based on the friction velocity $h^{+}$was 
approximately 93.9. To generate a turbulent boundary layer at the inlet with the desired boundary layer thickness and freestream velocity, the flow was recycled and scaled from a plane $10 \delta$ downstream from the inlet. A subroutine was written in Code_Saturne that followed the scheme developed by Lund et al. [19] to recycle and scale a turbulent boundary layer. The MVG was placed $6 \delta$ downstream of the recycle plane and the outlet was placed a further $10 \delta$ downstream of the MVG. Periodic boundaries were enforced in the spanwise direction at a distance of 5.71ס. A no-slip boundary condition was enforced on the wall and a symmetric boundary was placed $6 \delta$ above the wall. The MVG vane was centered in the spanwise direction of the domain. The mesh generated for simulations had between 14.03 to 16.60 million cells and was generated with ANSYS ICEM using its block-base mesher. The averaged $\mathrm{y}^{+}$on the wall was 0.5 and on the MVG was 2. The mesh resolution in the streamwise $\left(x^{+}\right)$and spanwise $\left(z^{+}\right)$were both less than 12.5. Sensitivity of MVGs to mesh resolution has been previously investigated by the authors [6]. The mesh of the MVG vane and the surrounding wall is shown in Fig. 2.

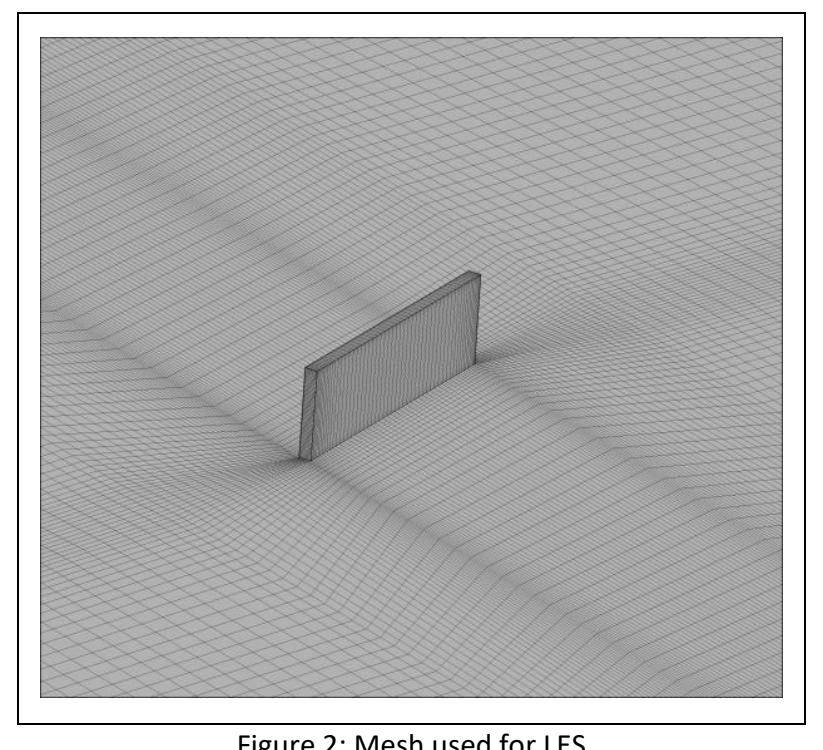

Three different vane-types were used for this study: rectangular, triangular, and e423-Mod vanes. The vanes were placed at an angle of $18.5^{\circ}$ relative to the oncoming flow which has been previously observed to be the optimum angle. The rectangular vane was further simulated at $16^{\circ}$ and $23^{\circ}$ to show the influence the angle of attack of the vane has on the vortex. The e423 airfoil shaped vane has been simplified to the camber line of the airfoil and with constant thickness. The MVG vanes had a thickness of $1 / 7 \mathrm{~h}$. 


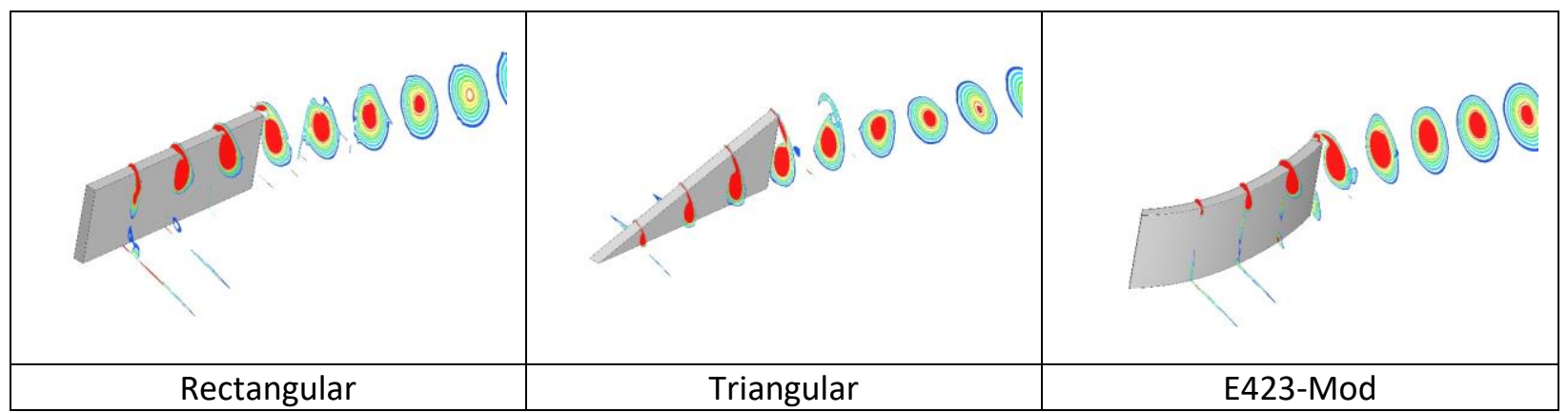

Figure 3: MVG vanes

Each of the simulations were run for at least 20 flow through periods to allow the turbulent flow to develop and mature. The simulations were run for a further 10 flow through periods to record the statistics of the flow. Slices of the flow on and downstream of the MVG were extracted and analyzed as part of this paper's analysis.

\section{Results}

\section{Flow dynamics on the MVG}

MVG vanes function by creating a pressure differential across the vane causing the flow to roll-up at the vane's tip causing a vortex to form, much like an airplane wingtip. However, the characteristics of the generated vortex and secondary flow structures can vary greatly depending on the vane shape. As an introduction, five slices of the $x$-vorticity are displayed in Fig. 4 to illustrate the formation and growth of the vortex on a rectangular vane at $18.5^{\circ}$. Since the MVG is embedded in a turbulent boundary layer, the MVG is subjected to chaotic flow fluctuations of turbulence which influences the vortex formation and the secondary flow structures. For reference, the viscous sublayer is $6.3 \%$ of the vane height and the buffer zone of the boundary layer extends to $37.8 \%$ of the vane height. Extracting the flow at a random time step, Fig. 3 shows a coherent vortex forming quickly on the vane's tip. After $50 \%$ of the vane length, the newly formed vortex becomes more erratic and can become briefly detached from the vane's tip. By the end of the MVG vane, the vortex is characterized by a concentrated pocket of strong vorticity whose position wanders. Averaging the flow over time, the vortex structure becomes diffused but uniformed. As with the instantaneous results, the flow rapidly rolls-up on the leading edge of the vane tip. The vortex continues to roll-up until about $50 \%$ to $75 \%$ of the vane length where it detaches from the vane. Contrary to the instantaneous results, the time-averaged vortex has already begun to diffuse by the time it leaves the vane. Immediately downstream of the vane, the wake of the vane is visible in both the instantaneous 
and time-averaged results but it quickly dissipates. Included in Fig. 4 are the $\left\langle v^{\prime} v^{\prime}\right\rangle$ and $\left\langle w^{\prime} w^{\prime}\right\rangle$ fields demonstrating the unsteadiness of the vortex core in both horizonal and vertical direction as it forms on the MVG.

During the vortex formation on the rectangular vane, a number of secondary flow features appear. On the leading edge of the rectangular vane, a zone of flow separation develops which is illustrated in Fig. 4 by black line in the vorticity plots and noted in previous research [6]. The separated flow on the vane is disrupted by the formation of the vortex and after half the length of the vane, the flow reattaches on the suction side of the vane. In return, the separated flow on the vane introduces unsteadiness into the vortex formation. Decreasing the vane angle from $18.5^{\circ}$ to $16^{\circ}$ slightly decreases the zone of separated flow while increasing the vane angle to $23^{\circ}$ slightly increases the zone of separated flow. A secondary vortex develops at a third of the height of the vane near to the leading edge of the vane and is visible in the first two slides in Fig.4. This secondary vortex is short lived and disappears at half the length of the vane.

The $x$-vorticity, $\left\langle v^{\prime} v^{\prime}\right\rangle$, and $\left\langle w^{\prime} w^{\prime}\right\rangle$ fields are displayed for the triangular and the e423-Mod vane in Fig. 5 and 6, respectively. The vortex formation and behavior on the triangular and the e423-Mod vanes share similarities and differences to the vortex generated on the rectangular vane. On the triangular vane, the vortex is formed by a continuous roll-up of the flow similar to that of a delta wing. Since the vortex formation begins near the wall, no secondary flow features can form on the leading edge of the vane. The formation of the vortex leaves the vortex close to the wall when departing the vane which has consequences for the vortex downstream of the vane and will be discussed later. The vortex displays less a chaotic nature and its path fluctuates less possible due to the vortex forming nearer to the wall and having stronger vorticity. The vortex formation on the e423-Mod vane is more in common with the rectangular vane. As with the rectangular vane, vortex formation begins quickly on the vane's tip as the pressure differential across the vane causes the flow to roll-up into a vortex. Due to the more aerodynamic shape of the vane, the pressure differential across the vane is far greater than for the rectangular vane leading to a vortex of stronger strength. The aerodynamic shape of the vane also reduces the relative angle of the leading edge to the oncoming flow preventing separated flow from occurring on the vane. The fluctuations in the vortex position was observed to be less in comparison to the rectangular vane which may be due to absence of any secondary flow features on the leading of the vane and/or stronger vortex. 
In spite of the differences in vortex formation on the three difference vanes, all three vanes have common secondary flow features elsewhere in the flow field. On the wall, the spanwise flow is pulled towards the vane on the suction side of the MVG and wrapped around the primary vortex. The magnitude of the velocity in the spanwise flow increases as it nears the vane. Near the wall, the no slip boundary condition leads a zone of negative vorticity. On the pressure side of the vane, the flow is pushed away from the vane in the spanwise direction. As with the suction side of the vane, a zone of negative vorticity forms near the wall due to the no slip boundary condition. The flow reaches a maximum spanwise velocity approximately $0.1 \mathrm{~h}$ above the wall and then deaccelerates in the normal direction from the wall leading to a pocket of positive vorticity on the pressure side of the vane. Downstream of the vane, the zones of negative vorticity on the suction and pressure side of the vane partially merge. The pocket of positive vorticity on the pressure side of the vane propagates downstream but quickly decays and by about $5 \mathrm{~h}$ downstream it has completely decayed. 


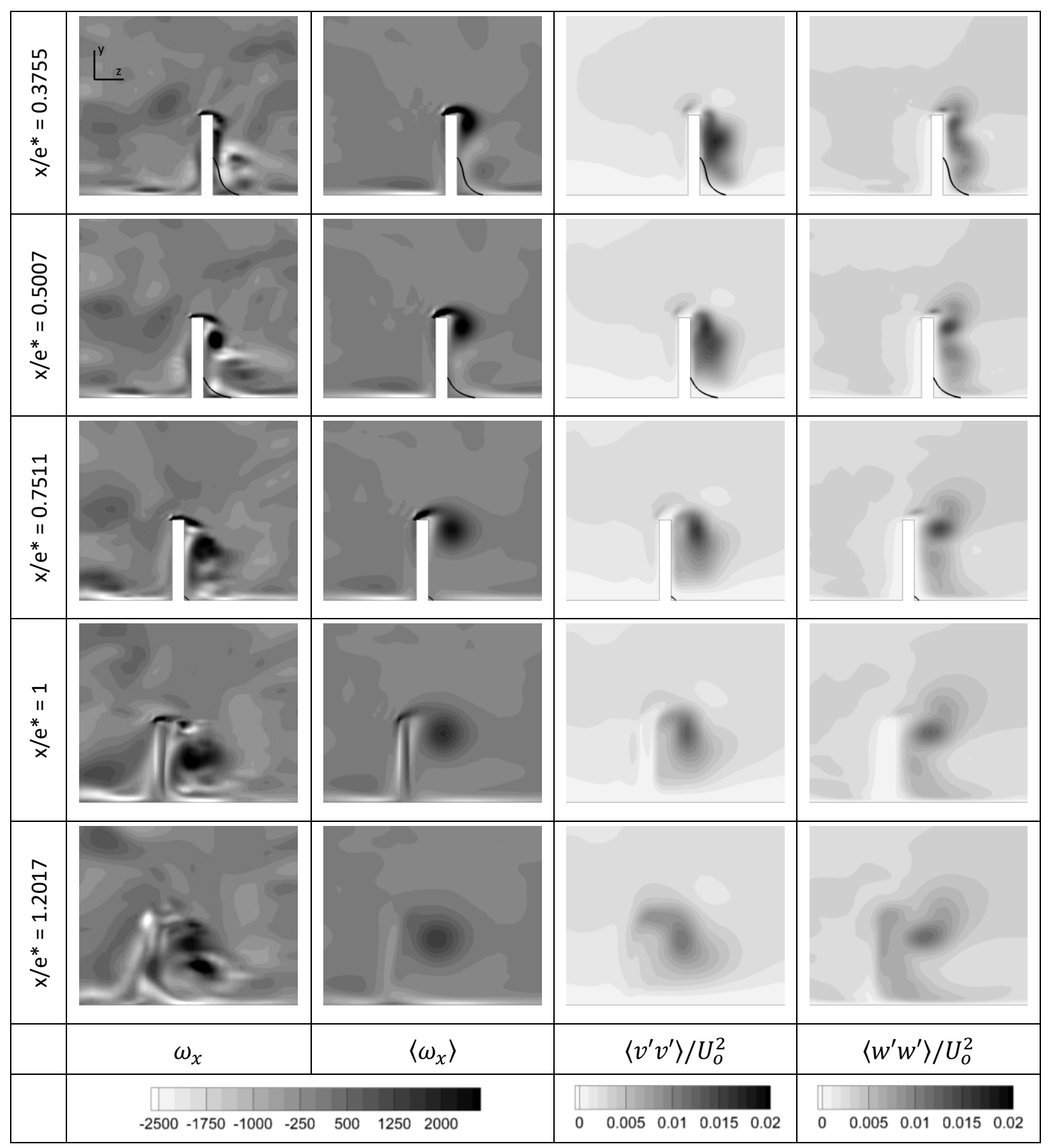

Figure 4: Slices in z-y plane of the $\omega_{x},\left\langle v^{\prime} v^{\prime}\right\rangle$, and $\left\langle w^{\prime} w^{\prime}\right\rangle$ fields on the rectangular MVG vane at $18.5^{\circ}$ (black line is the isoline of $u=0 \mathrm{~m} / \mathrm{s}$ ). 


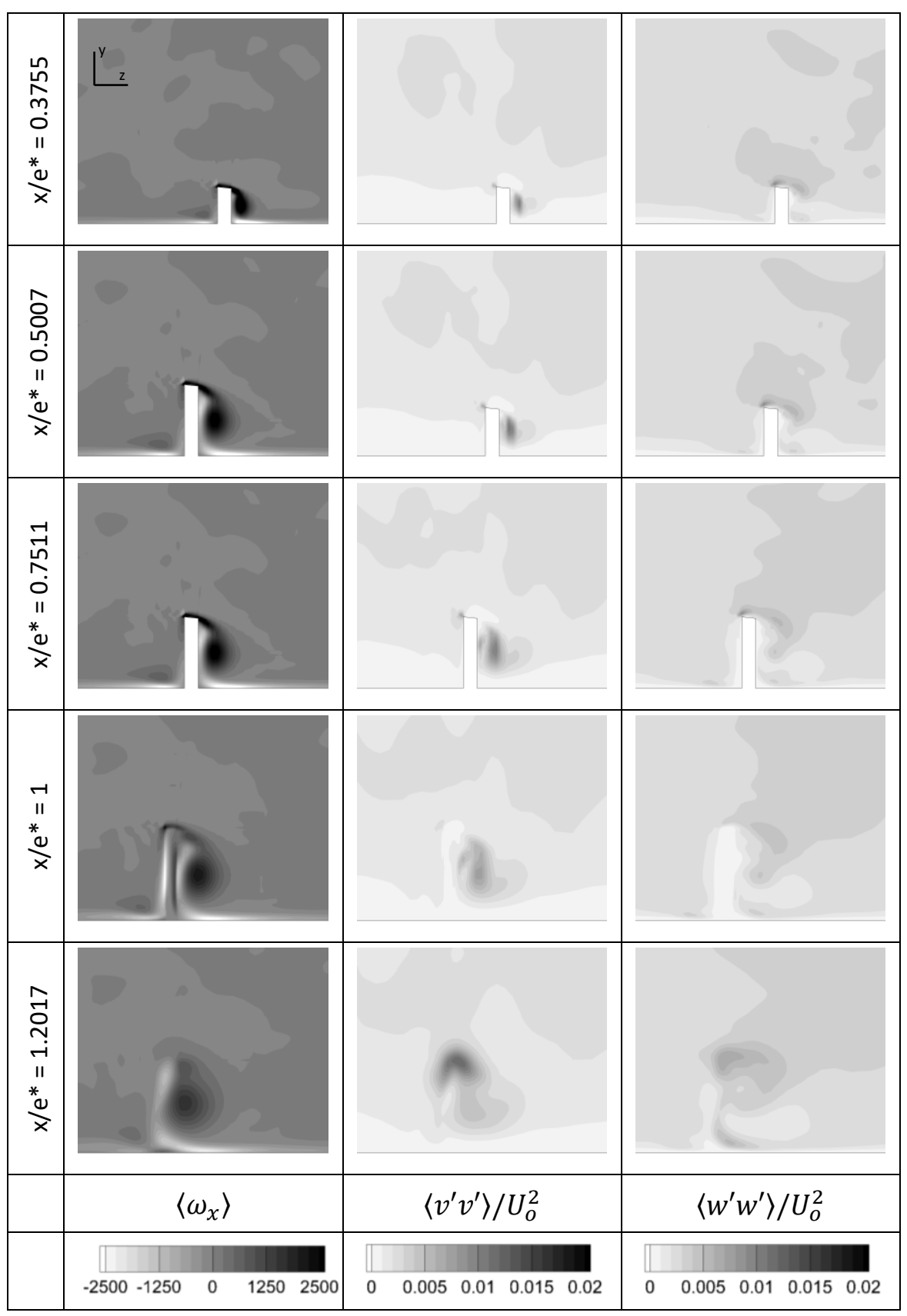

Figure 5: Slices in $z-y$ plane of the $\omega_{x},\left\langle v^{\prime} v^{\prime}\right\rangle$, and $\left\langle w^{\prime} w^{\prime}\right\rangle$ fields on the triangular MVG vane at $18.5^{\circ}$ 


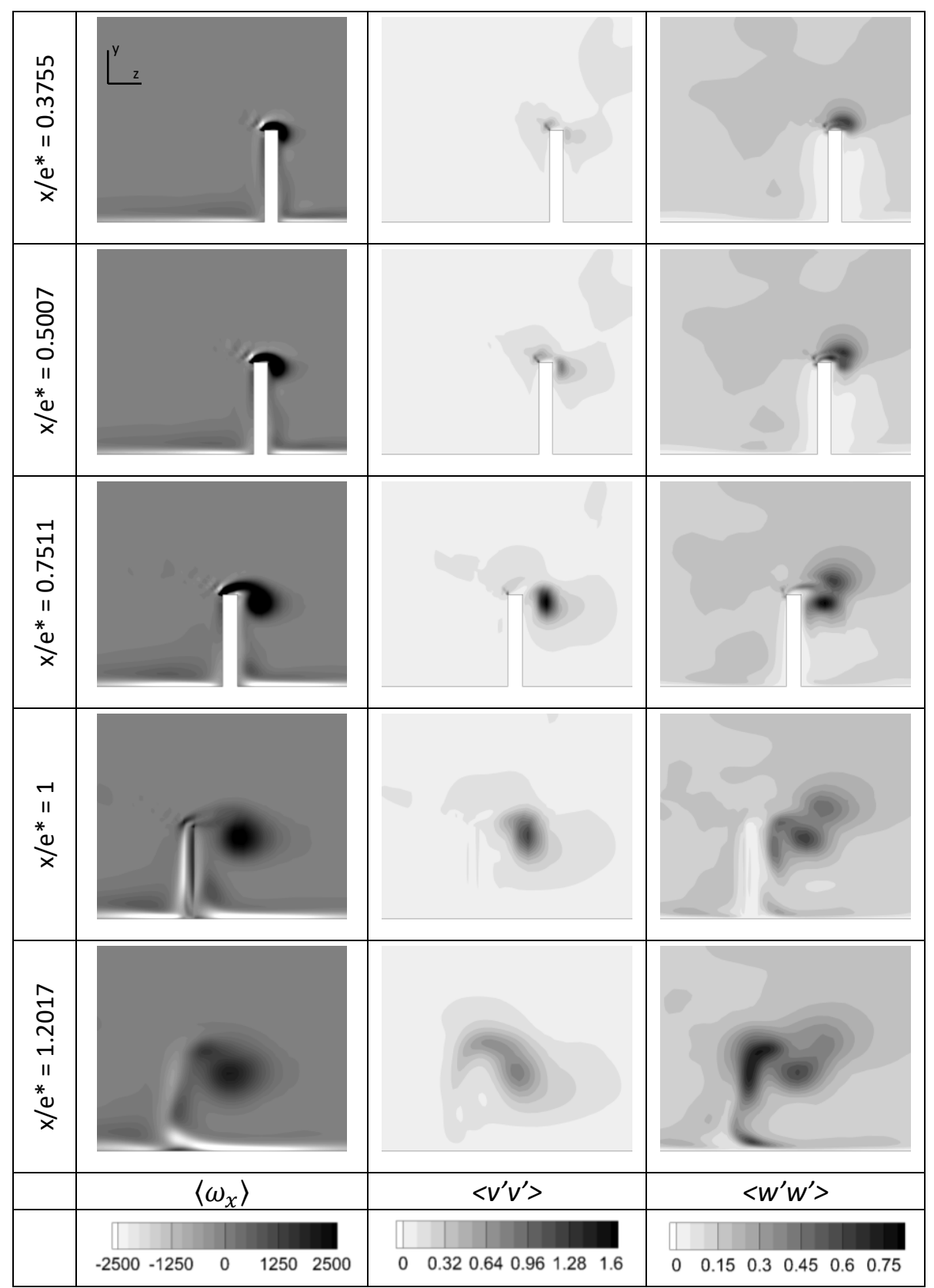

Figure 6: Slices in z-y plane of the $\omega_{x},\left\langle v^{\prime} v^{\prime}\right\rangle$, and $\left\langle w^{\prime} w^{\prime}\right\rangle$ fields on the e423-Mod MVG vane at $18.5^{\circ}$

\section{Downstream flow dynamics}

After forming on the MVG, the vortex propagates downstream as it decays. The formation process of the vortices discussed in the previous section heavily influences on how the vortex behaves downstream of the MVG. Five different parameters were calculated to evaluate and characterize the vortex: trajectory, peak vorticity, circulation, circulation decay, and vortex radius. There parameters were sampled between $1 \mathrm{~h}$ and $30 \mathrm{~h}$ downstream of the MVG. The vortex paths were determined by the lambda- 
2 criterion; the vortex core path was also found to nicely correspond with the maximum vorticity in the vortex. The radius of the vortex was approximated by obtaining the mean distance of the isocline of $50 \%$ of the peak vorticity to the vortex core. The circulation of the vortex was calculated by computing the surface integral of the vorticity vector dotted with the unit vector. For the enclosed work, the unit vector corresponded with the direction of the freestream velocity yielding the vortex's circulation in the streamwise direction.

$$
\Gamma=\iint \boldsymbol{\omega} \cdot \widehat{\boldsymbol{n}} d S .
$$

To avoid any numerical noise in the flow field, the vorticity was clipped to $1 \%$ of the peak vorticity at $x / h=1$ when calculating the circulation.

For the rectangular vane at $18.5^{\circ}$, the vortex leaves the vane at height of approximately of $0.8 \mathrm{~h}$ from the wall. The vortex initially travels closer to the wall by about $0.1 \mathrm{~h}$ until it reaches $4 \mathrm{~h}$ downstream of the vane. The vortex experiences a little decay at first but the decay rate increases quickly with distance as the vortex expands in area and vortex core diffuses leading to a reduction in the peaky vortex. At $\mathrm{x} / \mathrm{h}=4$, the vortex core shifts away from the wall as the vortex begins decay. The vortex experiences intense decay of the circulation and reaches a maximum in decay at $x / h=8$. The decay of the circulation slows after $8 \mathrm{~h}$ and the decay slowly decreases as the vortex propagates downstream. The vortex retains $47 \%$ of its original circulation at $30 \mathrm{~h}$. The peak vorticity in the vortex core experiences nearly an exponential decay as the vortex core diffuses. The increase of area of the vortex slightly slows down after $x / h=7$ but the cross-sectional area of the vortex steadily increases as it travels downstream. In addition to the vertical displacement of the vortex, the vortex displaces in the horizontal direction due to initial momentum of the vortex from its formation. The vortex displaces by about $1 \mathrm{~h}$ in the spanwise direction before the vortex loses momentum and the vortex's horizontal travel stagnates.

As discussed in the previous section, the strength of the vortex is directly related to the angle of the vane. This relationship leads to the vortex from the vane at $16^{\circ}$ to possesses $79 \%$ of the initial strength and the vane at $23^{\circ}$ possesses $129 \%$ of the initial strength of the vortex from the vane at $18.5^{\circ}$. The differences in the initial strength of the three vortices leads to different downstream behavior. The circulation of the vortex generated with the vane at $16^{\circ}$ experiences much less decay and reaches $x / h=30$ with $56 \%$ of its initial strength. The vortex takes a similar trajectory to that of the vortex generated by the vane at $18.5^{\circ}$. Alternatively, the circulation of the vortex generated with the vane at $23^{\circ}$ decays much more rapidly and reaches $30 \mathrm{~h}$ with only $41 \%$ of its initial strength. The vortex is deflected away from the 
wall much sooner at $\mathrm{x} / \mathrm{h}=3$ and travels much further away from the wall. The vortex also displaces further in the spanwise direction, almost $2 \mathrm{~h}$ by the time the vortex reaches $\mathrm{x} / \mathrm{h}=30$.

The initial of the vortex generated from the triangular vane at 18.5 is a compact, high vorticity system that is only $0.6 \mathrm{~h}$ distance from the wall. The vortex prorogates away from the wall as soon as it leaves the vane but the vortex's vertical displacement stagnates at approximately $0.7 \mathrm{~h}$. The vortex however decays very rapidly due to its initial distance from the wall in addition to the vortex diffusing. The strong initial decay of the circulation leaves the vortex with only $57 \%$ of its initial strength at $x / h=10$, and the continuous interaction with the wall leaves the vortex with only $17 \%$ of its initial strength by $x / h=30$. The cross-sectional area of the vortex rapidly increases due to the diffusion of the vortex, but by $\mathrm{x} / \mathrm{h}=14$ has reached its maximum size and begins to shrink.

The vortex of the e423-mod vane at $18.5^{\circ}$ also begins as a compact, high vorticity system with the highest peak vorticity and circulation out of the simulated MVGs. The vortex leaves the vane with an initial height of $0.8 \mathrm{~h}$, but as with the rectangular vanes, the vortex drifts towards the wall leading to the vortex to interact strongly with it. The vortex core is deflected away from the wall at $\mathrm{x} / \mathrm{h}=4$ but experiences a maximum in circulation decay at $\mathrm{x} / \mathrm{h}=7$. The vortex continues to experience much higher circulation decay than any of the other MVGs but still retains $43.7 \%$ of its initial circulation at $x / h=30$; its circulation is still higher than the rectangular vane at $18.5^{\circ}$ by $137 \%$ at this point.

The effects of the vortices on the wall are illustrated by the shear stress in the spanwise direction shown in Fig. 8. The figure also includes the paths of the minimum vorticity of the flow field and the vortex core. The primary and the secondary vortex structures that were formed by the MVG and discussed in the previous section can be observed in the shear stress contours. In between the two vortex structures is a zone of zero wall shear where a region of stagnated flow in the spanwise direction caused by the vane's wake. The region of stagnated flow and zero wall shear diminishes with the secondary vortex structure. The influence of the secondary vortex structure on the wall disappears by $5 \mathrm{~h}$ and much earlier for the triangular vane which disappears by $3.5 \mathrm{~h}$. The primary vortex structure affects the wall shear past $22 \mathrm{~h}$ although the vortex of the triangular vane is barely visible at this downstream point. The maximum wall shear is offset from the spanwise position of the vortex core and strongly correlates with the minimum in the vorticity in the flow. The maximum wall shear occurs on the downdraft side of the vortex. 


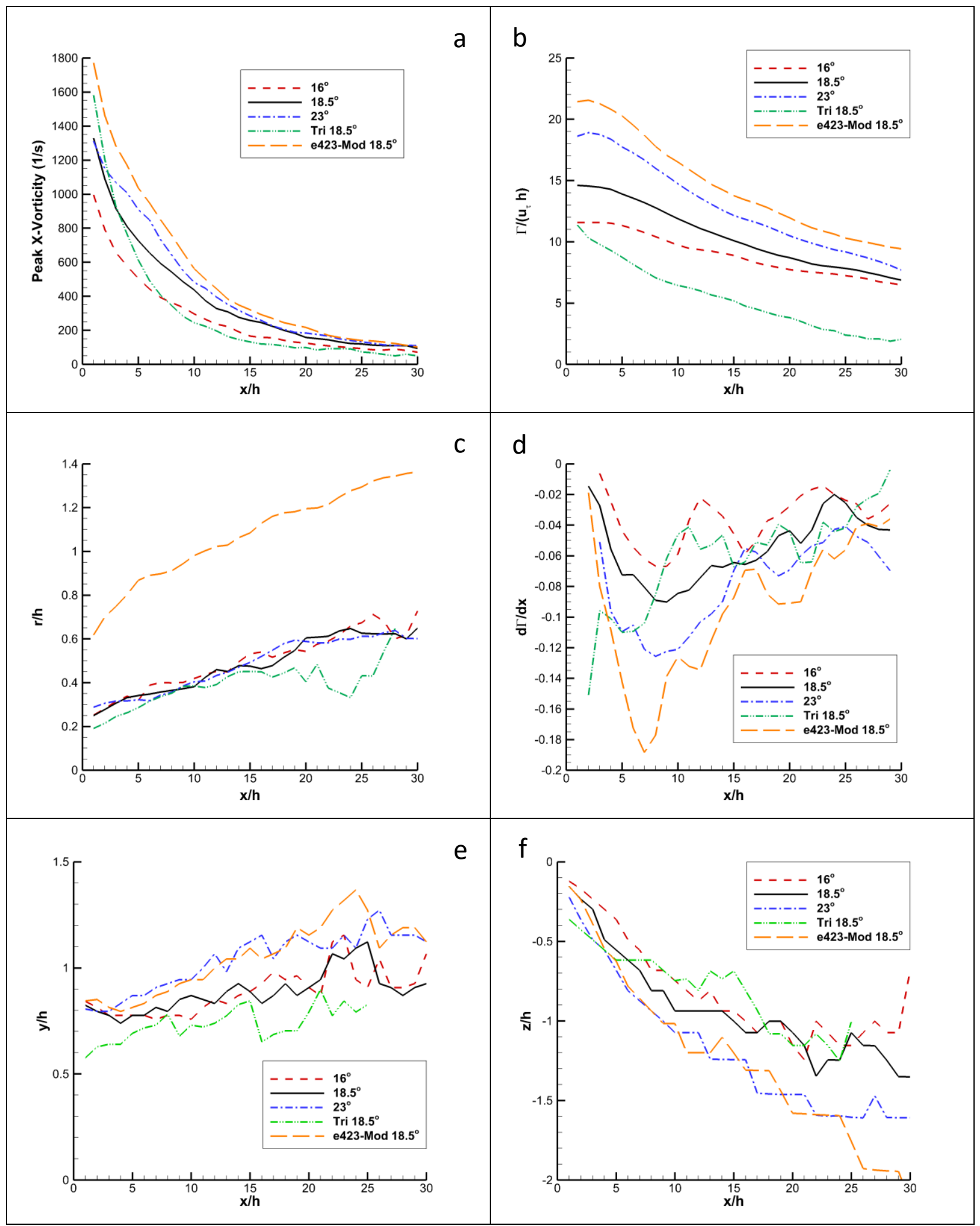

Figure 7: Vortex parameters (a. Peak vorticity, b. Circulation, c. Radius, d. Vortex decay rate, e. Vertical trajectory, f. Horizontal trajectory) 


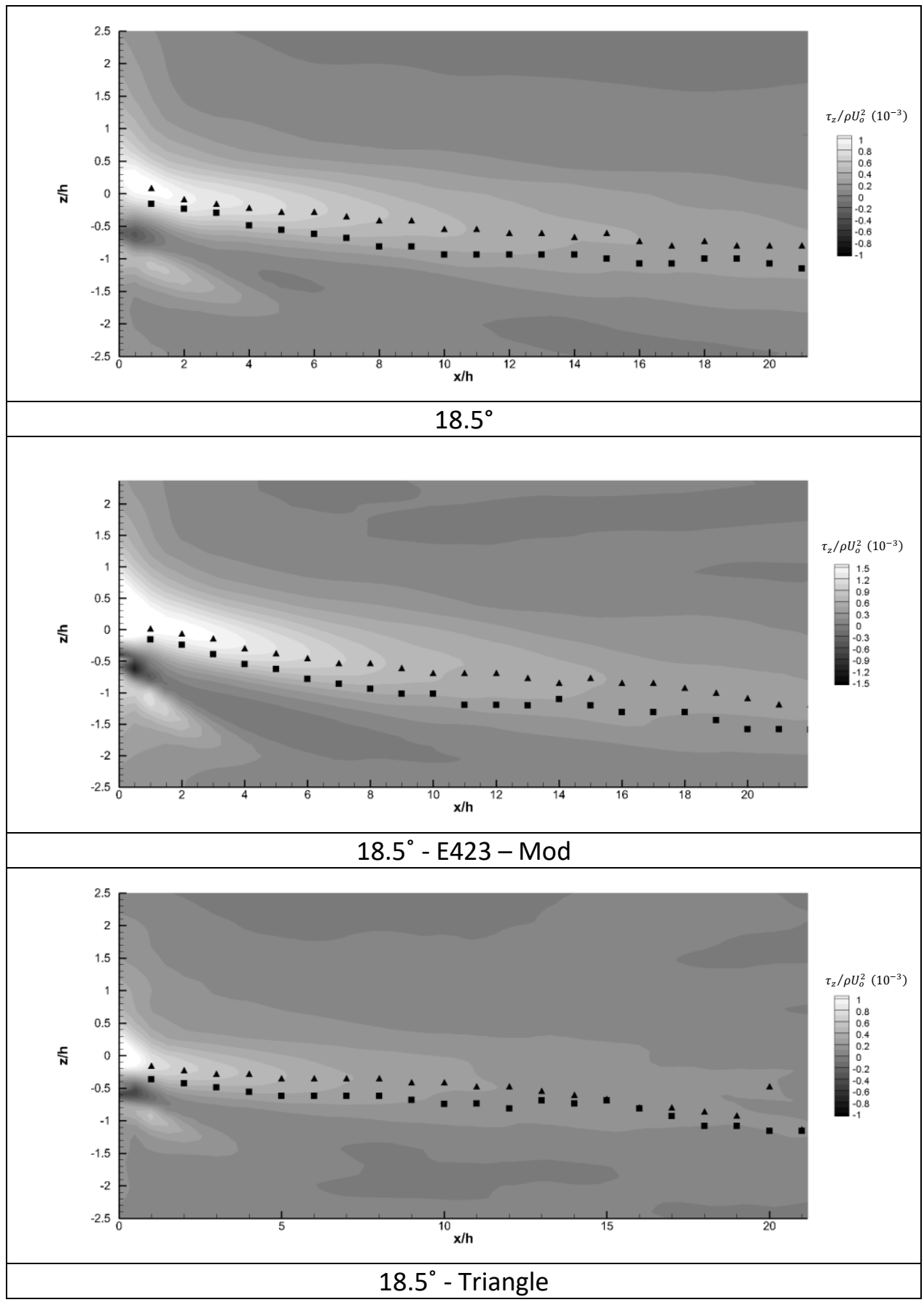

Figure 8: Contours of spanwise component of wall shear with the path of vortex core (square) and minimum X-Vorticity (triangle)

The normal stresses of the flow field were extracted at three downstream locations for the rectangular vane at $18.5^{\circ}$ and displayed in Fig. 9. Included in the plots in Fig. 9 is the X-vorticity isolines in order to illustrate the position of the vortex. At $x / h=1$, the $\left\langle u^{\prime} u^{\prime}\right\rangle$ stress is highly concentrated on the edge of the downwash side of the vortex. A high degree of $\left\langle u^{\prime} u^{\prime}\right\rangle$ stress is present in the wake of the vane and 
near the wall in the buffer zone of the boundary layer. A lobe of $\left\langle u^{\prime} u^{\prime}\right\rangle$ stress is present in the viscous layer on the upwash side of the vortex. By $x / h=5$, the $\left\langle u^{\prime} u^{\prime}\right\rangle$ stress has diminished significantly but remains concentrated on the downwash edge of the vortex. The $\left\langle u^{\prime} u^{\prime}\right\rangle$ stress further weakens in the vortex by $x / h$ $=10$ but remains strong in the buffer region of the boundary layer. The $\left\langle V^{\prime} v^{\prime}\right\rangle$ stress is concentrated in the vortex and reaching a maximum in the vortex core. The $\left\langle v^{\prime} v^{\prime}\right\rangle$ stress slightly diminishes from $\mathrm{x} / \mathrm{h}=1$ to 10 . The $\left\langle w^{\prime} w^{\prime}\right\rangle$ stress is also mainly concentrated in the vortex but the wake of the MVG leaves a high concentration of $\left\langle w^{\prime} w^{\prime}\right\rangle$ stress in the flow field that quickly diminishes. The maximum in the $\left\langle w^{\prime} w^{\prime}\right\rangle$ stress field is offset from the core of the vortex and is most intense on the upper edge of the downwash side of the vortex. A region of $\left\langle w^{\prime} w^{\prime}\right\rangle$ stress also occurs on the upwash side of the vortex near the wall. The concentration of the $\left\langle v^{\prime} v^{\prime}\right\rangle$ and $\left\langle w^{\prime} w^{\prime}\right\rangle$ stresses suggest the vortex core slightly wanders as presented in literature $[10,20,21]$ but wandering is dampened quickly downstream.

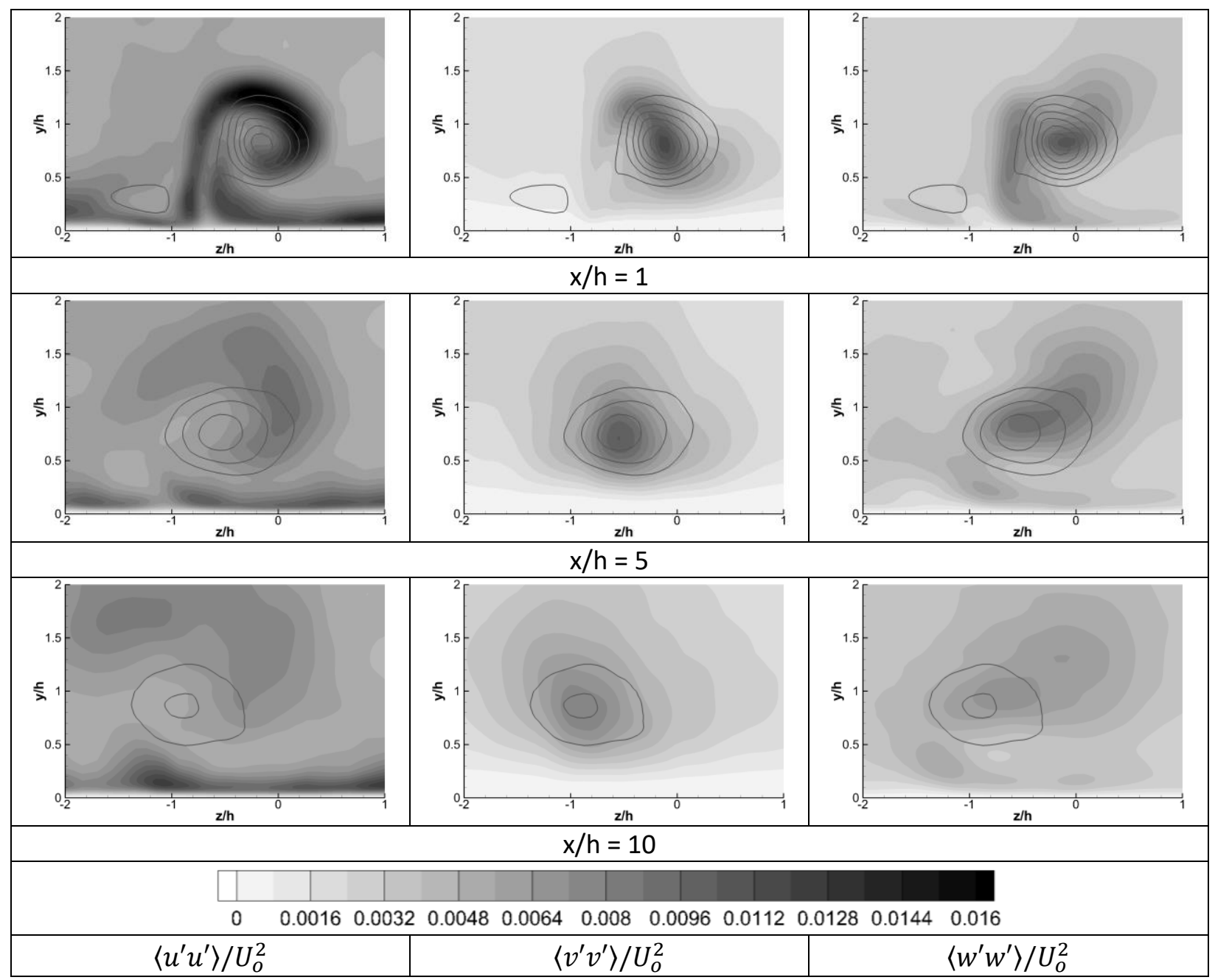

Figure 9: Turbulent kinetic energy, $\left\langle v^{\prime} v^{\prime}\right\rangle-\left\langle w^{\prime} w^{\prime}\right\rangle$, and $\left\langle v^{\prime} w^{\prime}\right\rangle$ fields of the rectangular vane at $18.5^{\circ}(X$-vorticity isolines from 200 to $12001 / \mathrm{s}$ at increments of $2001 / \mathrm{s}$ ) 


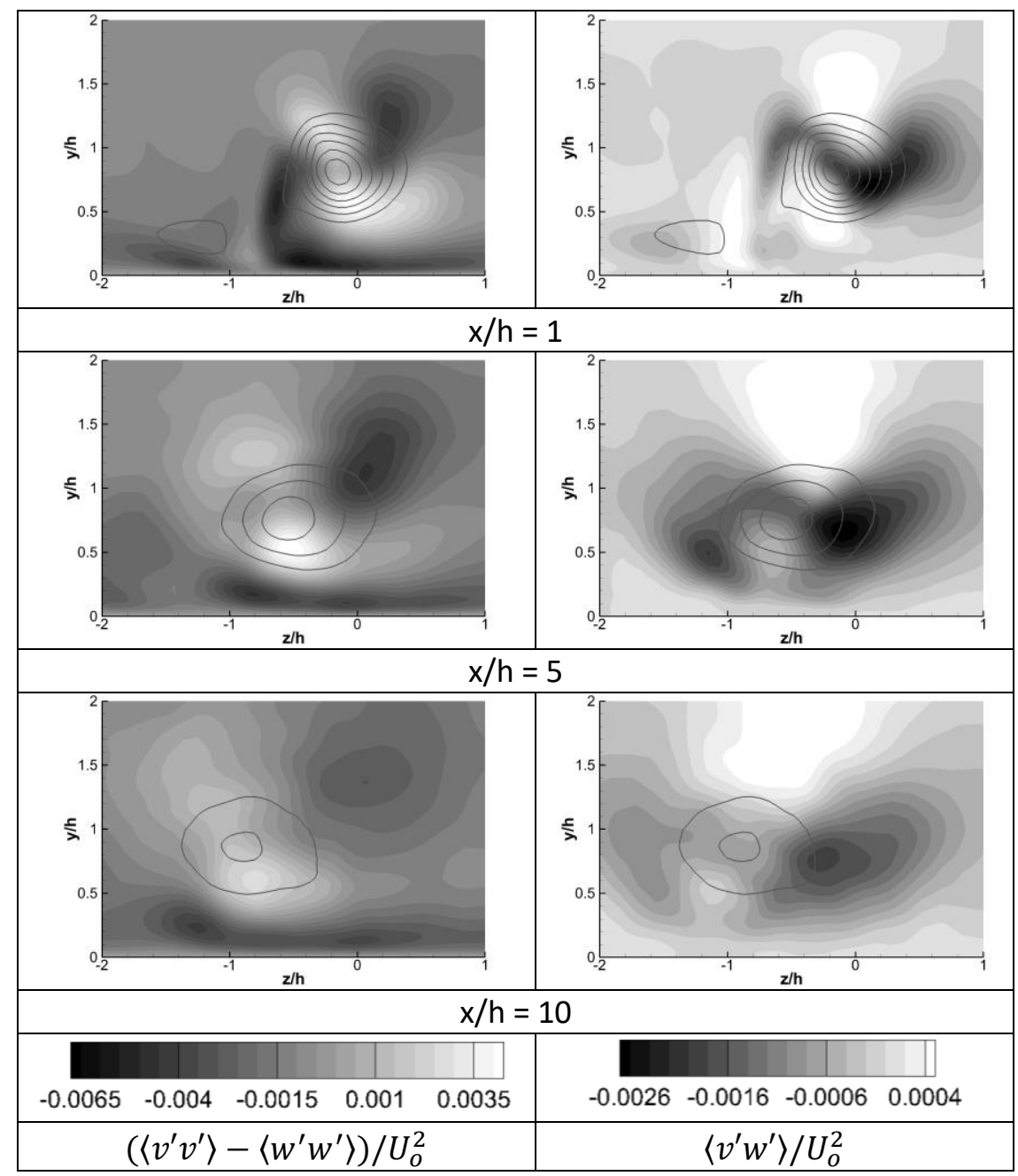

Figure 10: $\left(\left\langle v^{\prime} v^{\prime}\right\rangle-\left\langle w^{\prime} w^{\prime}\right\rangle\right)$ and $\left\langle v^{\prime} w^{\prime}\right\rangle$ fields of the rectangular vane at $18.5^{\circ}(X-$ vorticity isolines from 200 to $12001 / \mathrm{s}$ at increments of $2001 / \mathrm{s}$ )

The normal stress anisotropy $\left(\left\langle v^{\prime} v^{\prime}\right\rangle-\left\langle w^{\prime} w^{\prime}\right\rangle\right)$ and crossflow-plane shear stress $\left\langle v^{\prime} w^{\prime}\right\rangle$ fields are calculated in Fig. 10. The wake of the MVG vane contains a strong negative concentration of $\left\langle\left\langle v^{\prime} v^{\prime}\right\rangle-\right.$ $\left.\left\langle w^{\prime} w^{\prime}\right\rangle\right)$ stress along with a high gradient, and to a lesser extent of the $\left\langle v^{\prime} w^{\prime}\right\rangle$ stress. which causes rapid initial diffusion of the vortex as observed in Fig. 7a. A strong negative concentration of the $\left(\left\langle v^{\prime} v^{\prime}\right\rangle-\left\langle w^{\prime} w^{\prime}\right\rangle\right)$ stress is found on the upper downwash side of the vortex but a much stronger concentration is found near to the wall along with a stronger gradient. It is this interaction with the wall that appears to significantly diffuse the vortex. 


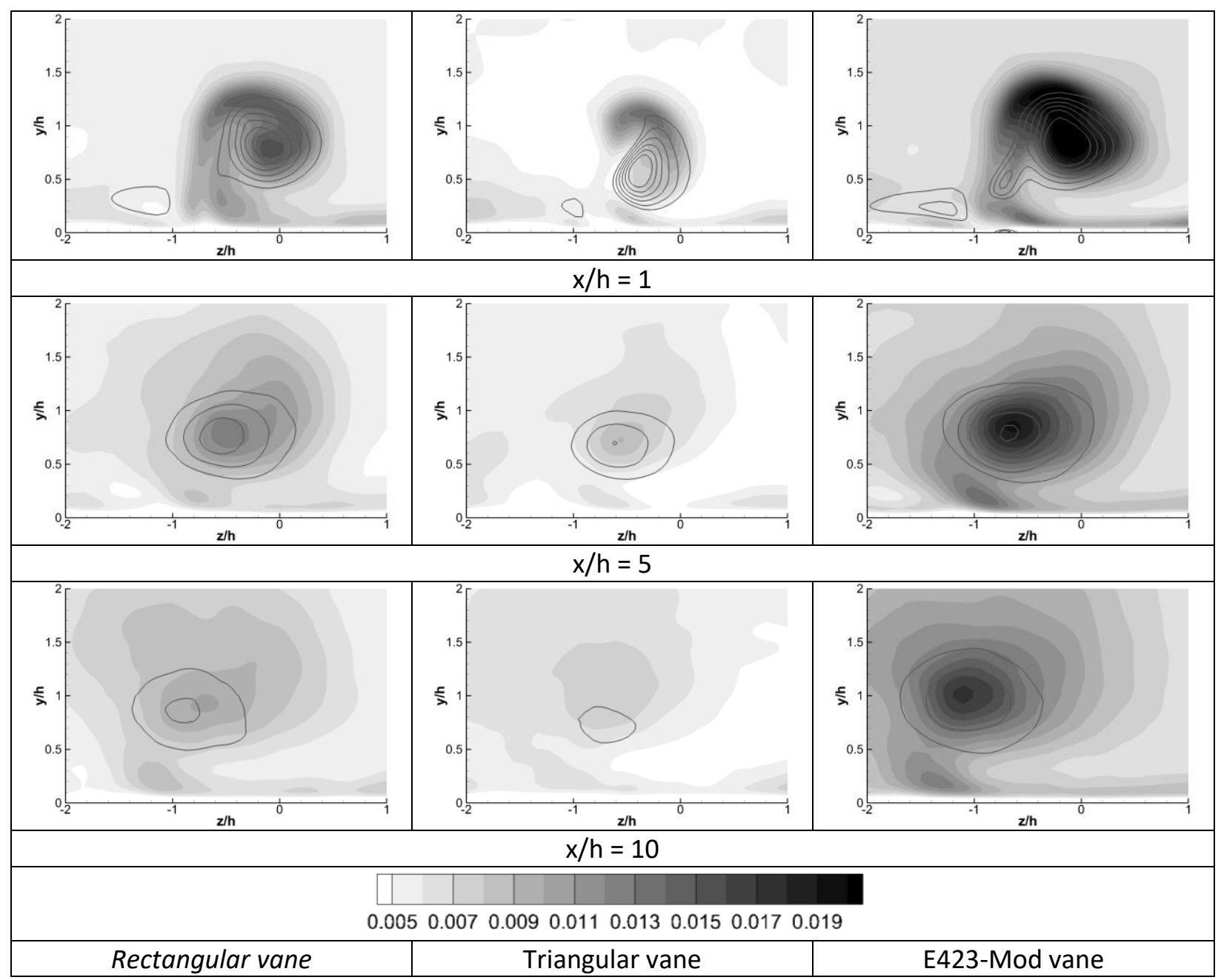

Figure 11: Turbulent kinetic energy ( $\left.k / U_{o}^{2}\right)$ of rectangular, triangular, and e423-Mod vanes at $18.5^{\circ}(X$-vorticity isolines from 200 to $12001 / \mathrm{s}$ at increments of $2001 / \mathrm{s}$ )

Finally, in Fig. 11 is the turbulent kinetic energy for the rectangular, triangular, and e423-Mod vanes. Comparing the turbulent kinetic energy to the individual normal stress in Fig. 9 for the rectangular vane, the $\left\langle u^{\prime} u^{\prime}\right\rangle$ stress dominates downstream of the, MVG but $\left\langle v^{\prime} v^{\prime}\right\rangle$ and $\left\langle w^{\prime} w^{\prime}\right\rangle$ stresses dominate in the vortex by $x / h=5$ and thereafter. Comparing the rectangular vane to other vanes, the triangular vane has significantly reduced turbulent kinetic energy. The turbulent kinetic energy is mainly concentrated at the top of the vortex from the triangular vane. Conversely the turbulent kinetic energy from the e423-Mod vane has a very similar distribution to the vortex of the rectangular vane but with twice the intensity level. 


\section{MVG Drag}

Consideration is finally given to the calculated drag on the MVG vane. Table 1 contains the drag of the MVG vane in comparison to the vortex circulation at $\mathrm{x} / \mathrm{h}=10$ and $\mathrm{at} \mathrm{x} / \mathrm{h}=30$. As with previous work on MVG efficiency [6], this study follows Ashill et al. [22] conclusion that the effectiveness of a VG is the strength of the vortex and the improvement in the shape factor of the boundary layer at the needed point for a given unit of drag. Considering the circulation only at $x / h=10$, the triangular vane had a much weaker vortex but was more efficient due to a significantly lower drag when compared to the rectangular and e423-Mod vanes. The e423-Mod vane has a much stronger vortex than the rectangular vane at $18.5^{\circ}$ but due to its high drag, its efficiency was only marginally better than the rectangular vane. When evaluating the vortex at $x / h=30$, the results changes significantly. Due to the quick decay of the vortex from triangular MVG, the triangular MVG dropped to having the worst efficiency. The vortices from both the rectangular at 18.5 and e423-Mod vanes decayed by nearly the same amount by $\mathrm{x} / \mathrm{h}=30$ giving them nearly equal efficiency. The rectangular vane placed at $16^{\circ}$ faired the best due to its low decay rate allowing it to achieve the best efficiency at $x / h=30$. In regards to manipulating the vane angle of the rectangular vane, increasing the angle of the vane increased the generated circulation while at the cost of increasing the drag of the vane, but the efficiency of the vane decreases with increase of angle.

In the computation of the MVG drag, the pressure force was found to contribute $70 \%$ to $80 \%$ of the drag on the MVG vanes while the viscous force accounted for remaining drag. This is not surprising due to the pressure differential on the MVG being fundamental to generation of the vortex.

\begin{tabular}{|l|c|c|c|c|c|c|c|}
\hline & \multirow{2}{*}{ Angle } & \multirow{2}{*}{$\mathrm{h}^{+}$} & \multirow{2}{*}{$\mathrm{C}_{\mathrm{D}}$} & \multicolumn{2}{|c|}{$\mathrm{x} / \mathrm{h}=10$} & \multicolumn{2}{c|}{$\mathrm{x} / \mathrm{h}=30$} \\
\cline { 5 - 8 } & & & & $\Gamma /\left(\mathrm{U}_{\tau} \mathrm{h}\right)$ & Ratio & $\Gamma /\left(\mathrm{U}_{\tau} \mathrm{h}\right)$ & Ratio \\
\hline Rectangular & $16.0^{\circ}$ & 90.86 & 149.31 & 9.73 & 0.0652 & 6.48 & 0.0434 \\
\hline Rectangular & $18.5^{\circ}$ & 95.36 & 202.77 & 11.88 & 0.0586 & 6.88 & 0.0339 \\
\hline Triangular & $18.5^{\circ}$ & 90.17 & 84.13 & 6.43 & 0.0765 & 1.89 & 0.0225 \\
\hline E423-mod & $18.5^{\circ}$ & 102.09 & 280.65 & 16.51 & 0.0588 & 9.42 & 0.0336 \\
\hline Rectangular & $23.0^{\circ}$ & 91.02 & 256.36 & 14.74 & 0.0575 & 7.69 & 0.0300 \\
\hline
\end{tabular}

Downstream of the MVG vane, the viscous force caused by the vortex in the streamwise direction was calculated in increments of $5 \mathrm{~h}$ and plotted in Fig. 12. The viscous force was calculated by subtracting the undisturbed flow from the channel flow effected by the vortex. The first increment in the plot, $\mathrm{x} / \mathrm{h}<$ 0 , corresponds to the increased viscous force on the wall between the leading and trailing edge of the MVG vane. The viscous force on this section of the wall is non-negligible but is small compared to the 
viscous forces downstream of the vane. Downstream of the vane, viscous force on the wall increases as the vortex begins to interact with the wall more strongly as shown previously with the spanwise shear stress. The viscous forces reach a maximum downstream between $15 \mathrm{~h}$ and $25 \mathrm{~h}$. However, the vortex from the E423-mod vane showed a rapid increase in viscous force, reaching a peak at $5 \mathrm{~h}$ to $10 \mathrm{~h}$, and then rapidly decreasing; this correlates to the rapid decay in the circulation of the E423-mod vane's vortex at this location. For some of the stronger vortices, viscous forces were still non-negligible past 50h.

Comparing the drag of the MVG vane to the downstream drag on the wall, the drag on the wall is only a fraction of the drag caused by the vane itself. For the three rectangular vanes, the accumulative drag on the wall drag from $0 \mathrm{~h}$ and $30 \mathrm{~h}$ was between $22 \%$ and $32 \%$ of the drag on the vane. For E423-mod vane the percentage was $16 \%$ while for the triangular vane it was $53 \%$. The ratio for the E423-mod vane is undoubtedly higher due to the viscous forces still having a strong effect after $30 \mathrm{~h}$. This demonstrates that the shape of the MVG vane has the strongest influence on the total drag of the MVG system.

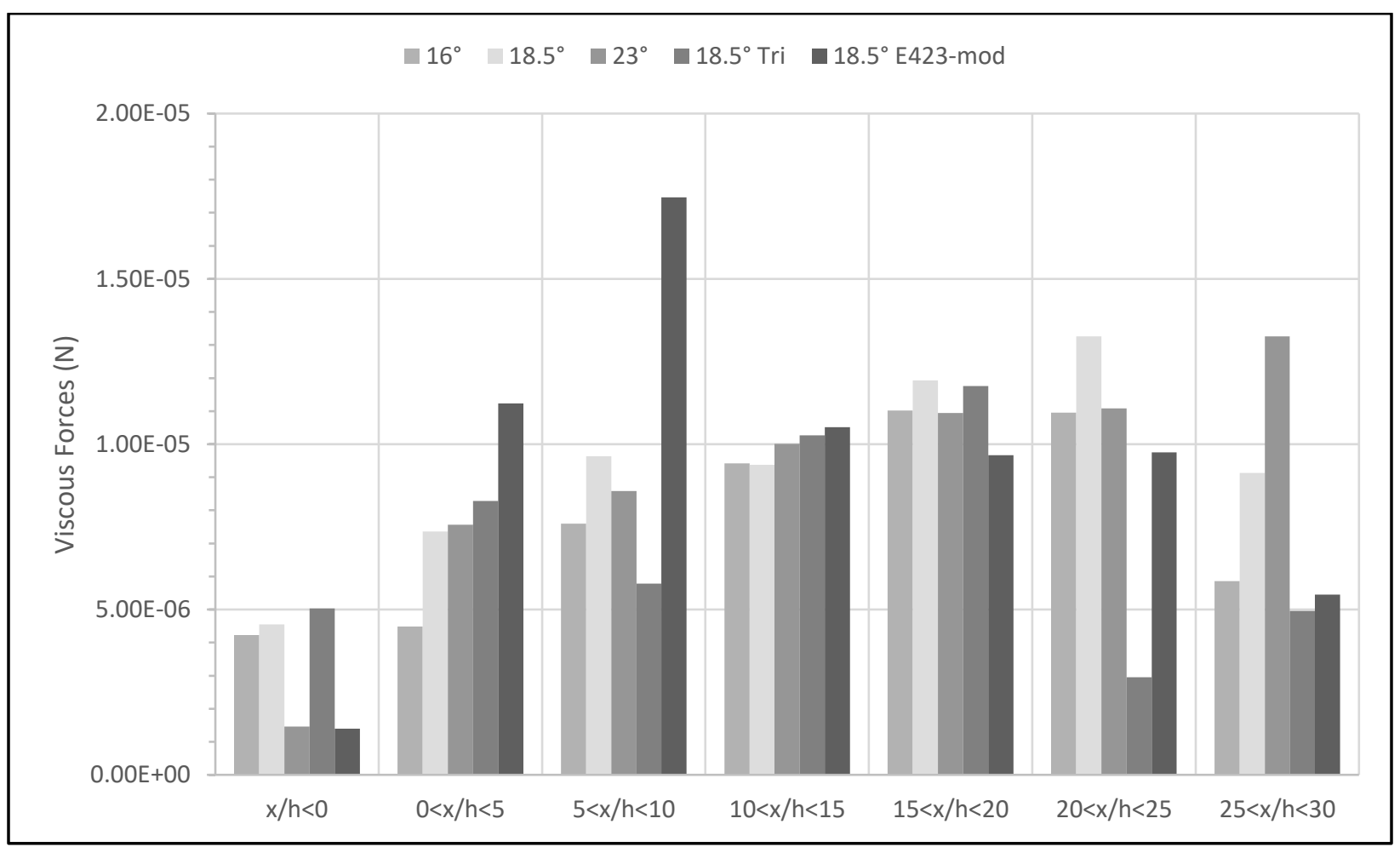

Figure 12: Viscous forces downtream of MVG vane 


\section{Conclusion}

A numerical study was conducted to investigate the flow physics of the five different MVG vanes and how the flow behavior of the MVG affected the downstream behavior of the generated vortex. The MVGs were studied in a turbulent boundary layer at $\operatorname{Re}_{h}$ of 2900 , or $h^{+}$of 93.9 . This study confirms the presence of a separation bubble on the leading edge of rectangular vanes that varies in time and affects the formation of the vortex. The superior aerodynamic shape of the e423-Mod and triangular vanes prevents the formation of a separation bubble and the vortex formation process was more stable. However, the roll-up of the vortex on the triangular vane caused the generated vortex to be formed very close to the wall. A number of secondary flow features also were observed to form on the MVG vane. On the pressure side of the vane, a weak vortex structure forms along with the primary vortex downstream. The formation of the vortex on the vane causes the spanwise flow to be pulled toward the vane creating a region of negative vorticity near the wall. And for the rectangular vane, a weak and short-lived secondary vortex forms at the corner between the vane and the wall.

Downstream of the vanes, the vortices rapidly diffuse due to Reynolds stresses present in the vortices. Initial circulation decay is slow but in the space between $x / h=5$ and 10 the vortex interacts strongly with the wall causing the circulation to decay quickly and for the vortices to travel away from the wall. The triangular vane's vortex decays very quickly throughout its life due to being formed very close to the wall. The other vortices reach $\mathrm{x} / \mathrm{h}=30$ with a reduction of roughly half of their initial strength. This decay behavior is reflected in the efficiency of the vanes. The triangular vane was found to be most efficient when its vortex was evaluated at $x / h=10$. However, when evaluating the vortex further downstream, the rectangular vane at $16^{\circ}$ was to found be most efficient due to the rapid decay of the vortex from the triangular vane. Pressure drag composes $70 \%$ to $80 \%$ of the drag on the MVG vane. The overall drag of the MVG vane itself is significantly higher than the increase in the skin friction due to the vortex. Future work needs to be conducted at higher Reynolds numbers to further establish the current conclusions.

\section{Acknowledgement}

The authors would like to acknowledge the technical support provided by Dstl and the EPSRC Turbulence Consortium under grant EP/L000261/1. 


\section{References}

[1] D. Rao and T. Kariya, "Boundary-layer submerged vortex generators for separation control - An exploratory study," in 1st National Fluid Dynamics Conference, (Fluid Dynamics and Co-located Conferences: American Institute of Aeronautics and Astronautics, 1988.

[2] J. C. Lin, "Control of Turbulent Boundary-Layer Separation using Micro-Vortex Generators," presented at the 30th AIAA Fluid Dynamics Conference, Norfolk, 1999.

[3] J. C. Lin, F. G. Howard, and G. V. Selby, "Small Submerged Vortex Generators for Turbulent Flow Separation Control," Journal of Spacecraft and Rockets, vol. 27, no. 5, pp. 503-507, 1990.

[4] W. R. Pauley and J. K. Eaton, "Experimental study of the development of longitudinal vortex pairs embedded in a turbulent boundary layer," AIAA Journal, vol. 26, no. 7, pp. 816-823, 1988/07/01 1988, doi: 10.2514/3.9974.

[5] G. Godard and N. Stanislas, "Control of a decelerating boundary layer. Part 1: Optimization of passive vortex generators "Aerospace Science and Technology, vol. 10, no. 3, pp. 181-191, 2006.

[6] A. P. Heffron, J. J. Williams, and E. Avital, "Numerical and Experimental Study of Microvortex Generators," Journal of Aircraft, vol. 55, no. 6, pp. 2256-2266, 2018, doi: 10.2514/1.c034550.

[7] I. M. M. A. Shabaka, "Longitudinal vortices imbedded in turbulent boundary layers. Part 1. Single vortex," Journal of Fluid Mechanics, Article vol. 155, pp. 37-57, 1985, doi: $10.1017 /$ S0022112085001707.

[8] J. Liu, U. Piomelli, and P. Spalart, "Interaction between a spatially growing turbulent boundary layer and embedded streamwise vortices "Journal of Fluid Mechanics, vol. 326, pp. 151-179, 1996.

[9] C.-S. Yao, J. C. Lin, and B. G. Allan, "Flow-Field Measurement of Device-Induced Embedded Streamwise Vortex on a Flat Plate," presented at the 1st AIAA Flow Control Conference, St. Louis, MO, 2002.

[10] K. P. Angele and F. Grewe, "Instantaneous Behavior of Streamwise Vortices for Turbulent Boundary Layer Separation Control," Journal of Fluids Engineering, vol. 129, no. 2, pp. 226-235, 2006, doi: 10.1115/1.2409327.

[11] P. R. Ashill, J. L. Fulker, and K. C. Hackett, "Research at DERA on Sub Boundary Layer Vortex Generators (SBVGs)," presented at the 39th Aerospace Sciences Meeting and Exhibit, Reno, 2001.

[12] P. R. Ashill, J. L. Fulker, and K. C. Hackett, "Studies of Flows Induced by Sub Boundary Layer Vortex Generators (SBVGs)," presented at the 40th AIAA Aerospace Sciences Meeting \& Exhibit, Reno, NV, 2002.

[13] B. G. Allan, C.-S. Yao, and J. C. Lin, "Numerical Simulation of Vortex Generator Vanes and Jets on a Flat Plate," presented at the 1st Flow Control Conference, St. Louis, MO, 2002.

[14] E. Wik and S. T. Shaw, "Numerical Simulation of Micro Vortex Generators," presented at the 2nd AIAA Flow Control Conference, Portland, OR, 2004.

[15] A. Heffron, J. J. Williams, and E. J. Avital, "Flow Seperation and Passive Flow Control on E387 Airfoil," in 54th AIAA Aerospace Sciences Meeting, (AIAA SciTech Forum: American Institute of Aeronautics and Astronautics, 2016.

[16] D. You, M. Wang, R. Mittal, and P. Moin, "Large-Eddy Simulations of Longitudinal Vortices Embedded in a Turbulent Boundary Layer," AIAA Journal, vol. 44, no. 12, pp. 3032-3039, 2006, doi: $10.2514 / 1.22043$.

[17] O. L. A. LÖGdberg, J. H. M. Fransson, and P. H. Alfredsson, "Streamwise evolution of longitudinal vortices in a turbulent boundary layer," Journal of Fluid Mechanics, vol. 623, pp. 27-58, 2009, doi: $10.1017 /$ S0022112008004825. 
[18] Y. Fournier, J. Bonelle, C. Moulinec, Z. Shang, A. G. Sunderland, and J. C. Uribe, "Optimizing Code_Saturne computations on Petascale systems," Computers \& Fluids, vol. 45, no. 1, pp. 103108, 6// 2011, doi: http://dx.doi.org/10.1016/j.compfluid.2011.01.028.

[19] T. Lund, X. Wu, and K. Squires, "Generation of Turbulent Inflow Data for Spatially-Developing Boundary Layer Simulations," Journal of Computational Physics, vol. 140, pp. 233-258, 1998.

[20] A. Cutler and P. Bradshaw, "Vortex/boundary layer interactions," in 27th Aerospace Sciences Meeting.

[21] R. D. Mehta, "Effect of a longitudinal vortex on a separated turbulent boundary layer," in Shear Flow Control Conference.

[22] P. R. Ashill, J. L. Fulker, and K. C. Hackett, "A Review of Recent Developments in Flow Control," The Aeronautical Journal, vol. 109, no. 1095, pp. 205-232, 2005. 